\title{
Paraíso e infierno. La imagen de México en las literaturas y él cine europeo y estadunidense
}

Friedhelm Schmidt

\section{Freie Universitiit Berlín}

En los últimos veinte años, el enfoque de las investigaciones sobre otras ellas sin tener en cuenta los trabajos autocríticos de la antropología, s de la sociología y de la crítica literaria, que reflejan cada vez más su propia percepción de otras culturas como un acto de apropiación violenta en que el llamado «otro» o «subalterno» no tiene voz ni palabra. Las teorías sobre el exotismo,2 la visión del otro, las experiencias de la alteridad o las posibilidades de la representación de voces subalternas en el texto ponen en duda el objetivismo de las ciencias humanas, que hasta mediados de siglo conservaron un cierto enfoque positivista. Aunque estas teorías a veces me parecen tener un enfoque exclusivamente académico (Spívak 1988) o proponen una tipología en parte ahistórica del encuentro violento de culturas (Todorov 1982, 1988), ${ }^{3}$ sí facilitan las interpretaciones de textos Literarios sobre otras culturas. Dentro de este contexto, me parece importante señalar que la crítica de textos exotistas no debe caer en la trampa de concebirse a si misma como un acto de crítica objetiva. Nuestro punto de vista está impregnado del mismo subjetivismo que se puede constatar en los textos de los escritores, directores de cine o de los viajantes europeos y estadunidenses que vinieron a México durante la primera mitad de este siglo. La diferencia que hay, en el mejor de los casos, entre estos textos o películas, por una parte y.nuestras investigaciones recientes por otra, es la existente entre el 
pseudo-objetivismo de muchos artistas que representaron otras culturas como si éstas no tuvieran su propia interpretación diferente del encuentro con el otro, que para ellos es el mismo viajante, y el autoconocimiento de un crítico que trata de tomar en cuenta sus propios prejuicios e idealizaciones en la percepci6n del otro, y que reflexiona sobre la historicidad y sobre el subjetivismo de sus puntos de vista; es decir, que hace un metaeomentario en el sentido en que Fredric Jamesan define esta noci6n para la crítica literaria (Jameson 1988).

Antes de interpretar algunos textos literarios y películas europeos yestadunidenses sobre México, quiero aclarar un poco la fascinación especial que el país tenía para muchos artistas e intelectuales durante las primeras décadas del siglo xx.

Por una parte, esta fascinaci6n es el resultado del proceso de modernizaci6n e industrialización en algunos países europeos y en los Estados Unidos, proceso que significa una fragmentación de la vida cotidiana para el individuo. Como resultado de esta fragmentación, la inseguridad personal crece, proceso que se intensifica por los nuevos conocimientos de la psicología y de la física (las teorías de Freud y Einstein respectivamente). Además hay una serie de cambios políticos (sobre todo el descenso del imperialismo clásico, la Primera Guerra Mundial y la Revoluci6n rusa) que, junto con los procesos mencionados antes, significan una crisis en la percepci6ndel mundo, visible tanto en la filosofía (por ejemplo; en las obras de Spengler [1923, 1970] YOrtega y Gasset 1970) como en las artes (los movimientos devanguardia: Dada, expresionismo, futurismo).

Al mismo tiempo, México se vuelve ellugár preferido para las proyecciones y utopías de los intelectuales europeos que buscan una renovación espiritual de su propia civilización o unos cambios políticos radicales. Las excavaciones en Teotihuacán entre 1906 y 1910 estimulan el interés en las culturas indígenas, en su religi6n, su vida aparentemente natural y no fragmentada. y sobre todo en su culto a la muerte. Por otra parte, la Revolución mexicana (1a primera del siglo, que termina-al menos los viajantes europeos y estadunidenses 10 ven así-con el éxito de las fuerzas revolucionarias) funciona como fuente de inspiración para las utopías de los intelectuales de izquierda. En esta primera etapa, la fascinación de México para los artistas es el resultado de una crítica de la supuesta decadencia de la civilización del Occidente, o el de un antiimperialismo romántico de ciertos grupos de la izquierda.

En los años 30 y 40, las razones para venir son otras: la estancia de los alemanes, españoles y algunos franceses es forzada; se van al exilio huyendo del fascismo ode la ocupaci6n de su país por los nazis, y eligen (si acaso pueden elegir) a México como lugar de exilio, porque el país inicia una política exterior decididamente antifascista durante el sexenio de Lázaro Cárdenas. Dos décadas después de esta segunda ola hay una tercera, de viajantes estadunidenses (1os 
beatniks y los hippies) que buscan en México una alternativa al «American Way of Life» con su puritanismo y su conciencia laboral estricta, y que rechazan a la civilización moderna para vivir una vida supuestamente más natural, integral y apasionada, o simplemente vienen para tener un acceso más barato a las drogas.

Mientras que todos los grupos mencionados antes critican de una $\mathrm{u}$ otra manera el estilo de vida o la política de sus propios países, el caso del cine estadunidense es diferente. Sobre todo las películas del género Western funcionan como una forma de legitimación del expansionismo de los Estados Unidos y del desplazamiento de lafrontier (es decir, de la frontera ideo16gica) hacia México, y los cambios en la representación de los mexicanos en el Western son un indicador de los cambios políticos.

Las visiones de México en las literaturas y el cine del siglo XX no se pueden entender sin tomar en cuenta el cambio en la percepción del país a partir de la intervención francesa y de la ejecución del emperador Maximiliano. Como lo ha afirmado Carlos Monsiváis, «a los ojos del 'mundo civilizado' .._el fusilamiento de Maximiliano ... le quita mucho del carácter de 'ex6tico' al país» $(1984,221)$. Ahora ya no es un paraíso en la zona tropical con su naturaleza desbordante, sino se convierte en la encarnaci6n de la barbarie" (como lo indica el título del libro México bárbaro, Turner 1969, 1974), en un lugar de violencia, habitado porindios primitivos, sucios y veleidosos. A partir de los años setentas del siglo pasado, se publican un sinnúmero de relaciones de viaje. en su mayoría ficticias, que más tarde se transforman en fuente 'hist6rica' de novelas de aventuras y de libros ilustrados. Estos últimos, de nuevo, forman parte de la lectura infantil de muchos de los viajantes, que escriben sobre México a comienzos del siglo.

El proceso aquí descrito es significativo para muchos viajeros: cuando inician sus viajes, ya tienen ciertas impresiones del país por vía de sus lecturas de textos que se basan en viajes ficticios; es decir, al comienzo no hay el viaje mismo, sino una relaci6n de un viaje ficticio, que es la fuente para un viaje real, que se transforma en texto otra vez. ( $\mathrm{Y}$ es precisamente este proceso de la construcción de textos literarios exotistas a partir de relatos ficticios que analiza Certeau 1986, 137-143.)

Considerando el cambio en las visiones de México a partir de la intervención fracasada de los Borbones, no sorprende que la primera película sobre México, realizada en 1894 bajo el título de Pedro Esquirel and DionecioGonzales-Mexican Duel, consiste solamente en una riña a cuchilladas de los dos protagonistas. En el cine de los Estados Unidos, y sobre todo en los Western, México está representado como un país en que el Estado no tiene el poder para imponer un sistema legal; es un país de crueles bandidos, revolucionarios cándidos y anarquistas infantiles, todos feos y estúpidos. por supuesto, que aterrorizan a las 
personas decentes (sí las hay, aunque sean muy pocas, y son menos feas, pero igual de estúpidas). La encarnación de los mexicanos crueles es el «greaser,» un hombre que es capaz de todo tipo de excesos criminales inmotivados. Así está representado en películas como The Greaser's Gauntlet, deD.W. Griffith (1910), The Greaser's Revenge (1911) y Bronco Billy and the Greaser (1914), y aun el rol de Pancho VíBa en Li/e of Villa, de D.W. Griffith (1Q14), cabe en el mismo cliché y satisface plenamente las expectativas del público en los Estados Unidos (García Riera 1987, 65-69).4

El caso de la representación cinematográfica de Pancho Villa puede ser un buen punto de partida para cualquier investigación sobre la imagen dẹ México en el cine norteamericano, porque aparece frecuentemente como protagonista principal en películas que corresponden mấs bien al género del Western que al cine histórico. Aunque en Lije 01 Villar la figura de Villa está descrita con cierta simpatía, no es posible diferenciar entre el típico «greaser» y el revolucionaría que lucha por una causa justa, sobre todo porque se refiere a esta última de una manera muy abstracta, y porque los revolucionarías actuan igual que los «greasers» de las películas mencionadas antes (Orenana 1991). Ni Villa ni otros revolucionarios son exclusivamente malos en las películas del período entre 1911 y 1914, pero esta imagen cambia de inmediato con la ruptura entre Villa y Carranza y con el bloqueo del puerto de Veracruz; es decir, la representación de la Revolución mexicana en el eme estadunidense corresponde perfectamente con los cambios de la política exterior del país.

Este fenómeno se puede constatar también en Viva Villa!, película realizada en 1934 por los directores Howard Hawks y Jack Conway. Mientras que, a partir de 1915, en el cine estadunidense los mexicanos están representados de una manera sumamente despectiva (Pike 1992,244), en Viva Villa! se trata de dar una imagen más bien positiva del héroe de la Revolución. Villa aparece como buena persona, pero un poco infantil e ingenuo, y en realidad no sabe mucho ni de la política ni del funcionamiento del Estado y de su economía (Welle 1992, 167169). Además, la actuación de Wallace Beery hace de este Western una especie de «screwball comedy» en que no se toma en serio ni la historia de México ni sus protagonistas reales (Mistron 1983,5). Pero aunque paraEmilio GarcíaRiera «en lo histórico, fue una falsificación de la Revolución mexicana no tan malintencionada como vulgar, o sea, al gusto del más ignorante espectador norteamericano» $(1987,220)$, el historiador del cine mexicano y estadunidense afirma al mismo tiempo que «en lo político, la película significó sin duda un paso conciliatorio, si se recuerda la mala fama norteamericana de Pancho Villa» (220). Este paso concilíatorio en una película de 1934 es, sin lugar a dudas, el resultado de la nueva política del presidente Franklín D. Roosevelt; es decir, tanto del New 
Deal como de la Good Neighborhood Policy, que no solamente tenían la función de restablecer la economía norteamericana después de la crisis económica mundial, sino además la de encontrar aliados en la lucha contrá el fascismo. ${ }^{5}$

En 1968, Buzz Kulik realiza otra película del mismo tema, Villa Rídes. En ella el protagonista ya no es el bandido infantil, sino un hombre serio, y los excesos de violencia no las ejecuta Villa, sino uno de sus compañeros. Pero lo más importante es la representación de la relación entre Villa y un tal Mr. Arnold, quien ayuda a los revolucionarios con su avión militar. Aunque al comienzo los motivos de Mr. Amold no son nobles, al final se convierte en un defensor de la causa revolucionaria, a no ser que afecte sus intereses económicos (Welle 1992, 170). Aquí, una vez más, el cine de Hollywood funciona como legitimación de la política exterior de los Estados Unidos. Después de la Revolución cubana, se busca otra vez una relación de good neighborhood con los países latinoamericanos en la Alianza para el Progreso. Dentro de esta política, los representantes del Estado-y, como lo muestra Villa Rides, también los directores del cine de Hollywood-se ven a ellos mismos como defensores de la libertad y de la democracia que ayudan a todos los que viven al sur del Río Bravo. A la ayuda económica de la Alianza para el Progreso, el cine añade el subsidio moral e ideológico para impedir otras revoluciones como la de Cuba.

Esta ideología de un proteccionismo en muchos casos paternalista que se basa en las ideas del Manifest Destiny (161-163) también es visible en The Magnificent Seven, el remake de Los siete samurai del director japonés Akira Kurosawa, filmado en 1960 por John Sturges. Una vez más, son los gringos que salvan a los pobres campesinos mexicanos de las amenazas, robos y de los excesos criminales del bandido Calvera. Aunque este Western muestra claramente que el estatus del clásico outlaw en el género está entrando en crisis a partir de Los años 60, los estereotipos de los mexicanos quedan intactos. ${ }^{6}$ Lo mismo se puede decir incluso de la parodia del género que realizó John Landis en 1986 con Three Amigos.

The Magnificent Seven no solamente tenía gran exito comercial sobre todo en Europa, sino que influyó de manera decisiva en la creación de Los llamados Spaghetti Westerns de Sergio Leone, Mario Camus y Sergio Corbucci, entre otros (Buscombe 1993,23-24). Estos directores, influidos por el movimiento antiímperiaLista de los años 60, se proponen la desmitificación de la ideología y del moralismo de las películas norteamericanas del género. Pero no desmitifican los estereotipos sobre México, sino que reducen las alusiones al país a sombreros, paisajes desérticos y la mención del peso como moneda nacionaL. Sí hay fiestas, indispensables requisitos de todas las películas sobre México, que en su .mayoría son más bien españolas con danzas y música del flamenco. 
Aunque, como ya 10 he dicho, el Westem es un caso aparte en el contexto de las representaciones de México en el cine y las literaturas modernas por su afiliación a la ideología oficial de la política norteamericana, hay algunas imágenes parecidas incluso en la literatura y el cine de artistas que simpatizan abiertamente con la Revolución mexicana. En México insurgente (Reed 1969, 1982), por ejemplo, Pancho Villa está representado de. una manera similar que en los Western, y los revolucionarios tienen las mismas características que los «greasers» del cine. Lo mismo se puede decir de los textos de Vladimir Maiakovskí (Schimmelpfennig 1992,88; Schneider 1973, 34-35). La diferencia más importante entre las obras de Reed, Maiakovski y la película inconclusa iQué viva México! (1931), de Sergeij Eisenstein, por una parte, y el cine Westem por otra, es que tanto los escritores como Eisenstein aceptan la posibilidad de un desarrollo autónomo de México sin la ayuda de un país supuestamente más avanzado y civilizado.

Aunque Reed simpatice abiertamente con la Revolución mexicana, incluye en su obra algunos de los estereotipos del México bárbaro y exótico del siglo XIX. En el primer capítulo de México insurgente hace una comparación un poco forzada entre este país y el Oriente. Escribe sobre la ciudad de Ojinaga en la orilla del Río Bravo:

Veíanse sús casas cuadrangulares de pardo adobe y, aquí y allá, la cúpula oriental de alguna vieja iglesia española. Era una zona desolada, sin árboles. No se podía menos que esperar ver surgir minaretes. $(1982,1)$

Esta descripción, más que darnos una imagen verídica de la arquitectura de la ciudad, revela la similaridad entre la función de México para los viajantes estadunidenses y la que tenía el Oriente para los viajantes europeos del siglo XIX. A partir de la expedición de Napoleón a Egipto, el Oriente se convirtió en el lugar de las proyecciones de deseos reprimidos y de pasiones nunca vividos (como es visible, por ejemplo, en la obra de Gustave Aaubert). En los reportajes de Reed, a pesar de que aparentemente describen la Revolución mexicana y caracterizan a su héroe Pancho Villa, hay algo de estas proyecciones. Reed insiste una y otra vez en el carácter apasionado y hasta fervoroso de los mexicanos, y lo compara con la frialdad y severidad de los soldados norteamericanos que luchan junto con las tropas de Villa, y que, para él, no encajan en un país apasionado (93-95).

John Reed no es el único escritor que busca en México el Oriente, que no solamente es el lugar de las proyecciones de deseos eróticos, sino además el lugar «histórico» del paraíso. El novelista inglés D.H. Lawrence, por ejemplo, tiene, en la época de la Primera Guerra Mundial, la idea de fundar una colonia 
aristocrática (Rananirn) con otros escritores y artistas, y cree que la localidad ideal para la realización de esta utopía se puede encontrar en México o en Nuevo México, sin que en ese entonces hubiera viajado a estos lugares (Pichardie 1988, 39-60). Partiendo de la idea de que la civilización del Occidente es «un árbol sin vidas y de que un futuro feliz solamente se puede encontrar en el Nuevo Mundo, Lawrence viaja a América en 1922 para realizar su sueño utópico. Por eso, Los diferentes lugares (Taos, Chapala y Oaxaca) que visita durante sus viajes en el Nuevo Mundo, se convierten en posibles localidades para la fundación de Rananim. Pero a la imagen del paraíso utópico se sobrepone la angustia por la supuesta amenaza por parte del otro. Esta angustia posiblemente fue provocada al comienzo por las lecturas infantiles de Lawrence, como lo supone José Emilio Pacheco (1964, 19-22). Pero ¿porqué entonces insiste Lawrence tantas veces en la existencia de amenazas, que nunca experimenta durante su estancia en México a pesar de la situación política del país en los años 20 ?

Al final de «Un paseo a Huayapa,» uno de los relatos de viaje en Mañanitas mexicanas, Lawrence $(1960, \cdot 1982)$ expresa su admiración hacia el cuerpo desnudo de uno de los indígenas del pueblo que se está bañando en un río. (Cito el texto del original, porque la traducción de Alberto Cardin no deja ver bien el contenido abiertamente sexual de lo que dice Lawrence.)

\section{And 1 , going round the little hummock behind the wild guava tree to throw away the papers ofthe picnic, carne upon a golden-brown young man with his shirtjust corning down over his head, but over no more of him. Hastily retreating, 1 thoughtagain what beautiful. suave, rich skins these people have; a sort ofrichness oftheflesh. Ir goes, .perhaps, with the complete absence of what we call 'spirit.' $(1960,31)$}

Dejando aparte por el momento el aparente racismo en las opiniones de Lawrence con respecto a los indígenas, me interesa interpretar las frases citadas con un enfoque más bien psicológico. El sentimiento de ser amenazado por los indígenas puede ser interpretado dentro del contexto de la fascinación de Lawrence por Los cuerpos de los hombres indígenas, que él expresa no solamente en este, sino en algunos de los otros relatos de viaje y en la novela La serpiente emplumada (1990, 1978)-sobre todo en la escena en que Ramón mata a un bandido con su cuchillo, escena que contiene muchas alusiones al acto sexual (1978, c. XIX). Lawrence proyecta su propio deseo homosexual en el indígena, y así el deseo vuelve como angustia por el objeto deseado. Para Lawrence, ahora es el indígena que, por su carácter animal y su falta de espíritu, encarna los deseos sexuales que el autor no puede aceptar en si mismo (Schmidt 1992, 66-67).7 
Con esta interpretación no quiero decir que el racismo de Lawrence se debe entender únicamente en términos psicológicos. $\mathrm{Al}$ contrario. Es que el resultado de la represión de los deseos homosexuales armoniza perfectamente con la ideología racista de Lawrence. que proviene de las ideas de Thomas Carlyle. Su afirmación de la inferioridad de la raza indígena se puede entender tanto en el contexto psicológico como en el político; es decir, en el del descenso del'Imperio Británico a partir de la Primera Guerra Mundial.

A comienzos de 1933, Aldous Huxley viaja al Caribe, Guatemala y México. Los motivos principales de este viaje son dos: primero, venir a México es parte de la preocupación continua de Huxley por la obra de D.H. Lawrence. Ésta había comenzado con el retrato de este último en la novela Point Counter Point (1928) Ycon la introducción a las cartas póstumas de Lawrence, publicadas por Huxley en 1932 (1962), Ytiene su punto culminante en la relación del viaje publicado en 1934 bajo el título Beyond the Mexique Bay y en la novela Eyeless in Gaza, de 1936 (1950, 1970), que en general es visto como el prodúcto literario de la emancipación de Huxley de la influencia de Lawrence (Bartlett 1964). y el segundo motivo es ver su propia cultura y sociedad por la distancia y estudiarla en lo que Huxley entiende como un laboratorio para esta investigación antropológica: una cultura primitiva y menos compleja que la europea,

Las sociedades salvajes son sencillamente unas sociedades civilizadas en pequeña escala y con la tapadera quitada. Podemos aprender a entenderlas sin grave dificultad. Y una vez que hemos aprendido a entender a los salvajes, descubrimos que, de paso, hemos aprendido a entender a los civilizados, (1970, 1245)

$Y$ todo esto con el fin de analizar el peligro de un regreso a lo primitivo en el fascismo. Estos motivos definen la imagen de México en las obras de Huxley. Mientras que Lawrence busca una alternativa a la vida moderna en los países industrializados, Huxley ve a México exclusivamente en función del análisis de su propia sociedad. y mientras qúe Lawrence ve a los indígenas como seres de otro mundo, Huxley quiere ver en México un estado anterior a la sociedad moderna, una cultura primitiva que es el núcleo de las sociedades modernas. La construcción permanente de paralelos entre el laboratorio de la investigación y las sociedades europeas en la prosa de Huxley deja desaparecer casi por completo las diferencias culturales. En este sentido, su obra es el contrapunto de la de Lawrence.

Pero al discurso racional de Huxley en Beyond the Mexique Bay se sobrepone de vez en cuando una imagen más emocional del país. y es aquí donde aparecen otra vez los estereotipos de la experiencia mexicana de Lawrence: las amenazas, 
el carácter animal de los indígenas, la falta de espíritu. Al parecer, la lectura de La serpiente emplumada que hace Huxley durante su viaje, deja sus huellas en el texto que a veces se presenta más como el producto de una experiencia literaria que él de una experiencia real. Al final, el laboratorio mexicano de Huxley se convierte en el mismo infierno que ya experimentó Lawrence (Schmidt 1992, 70-77).

En suma, se puede decir que en la literatura de los grandes novelistas ingleses que escribieron sobre México, yeso no solamente es cierto en los casos de D.H. Lawrence y Aldous Huxley, sino también en las novelas de Malcolm Lowry $(1990,1993) 8$ YGraham Greene $(1965,1990)$, prevalece la imagen de un «infierno que ha irrumpido donde debiera estar el paraíso» (Pacheco 1964,21).9

Los surrealistas franceses siempre se interesaron en el arte de las culturas supuestamente primitivas, un interés que se extiende, sobre todo a partir de los años 40 , a la antropología y a las culturas populares. Dentro de este contexto, no es de sorprender que para los surrealistas que vienen a Méxicoel país se convierta de inmediato en «el lugar surrealista por excelencia,» como lo ha afirmado André Breton en una entrevista con Rafael HeHodaro Valle (1986, 121). Mientras que muchos viajeros y exiliados-John Dos Passos, Alfons Goldschmidt, Boda Uhse y Anna Seghers, entre otros-se ocupan del muralismo, y sobre todo de la pintura de Diego Rivera (Badenberg 1992), para los surrealistas Antonin Artaud y André Breton es la pintura de dos mujeres, María Izquierdo y Frida Kahlo, que encarna mejor el espíritu de un surrealismo intuitivo (Breton 1946, y Artaud 1963, 1968) que, aunque sea muy diferente de la pintura surrealista europea, da lugar a comprobar las ideas de Breton sobre la validez universal de su teoría surrealista (Badenberg 142-144). Las interpretaciones de la pintura mexicana por parte de los surrealistas son, más que un descubrimiento de una pintura nueva, una forma de asegurarse de su propia visión del mundo. Lo mismo sucede en los casos de los textos de Artaud sobre su viaje (aunque sea ficticio) a la región de los Rarámuri, en los cuales quiere ver la encarnación del «buen salvaje» (Brotherston 1972, Le Clézio 1980), del único verdadero México-es decir, del México indígena-yen la introducción de Benjamin Péret a una antología de mitos, leyendas y cuentos populares de América Latina, en la cual afirma que en el pensamiento mítico y en la poesía indígena se puede constatar un uso surrealista del lenguaje (1960, 12- $t 3)$. Aunque los surrealistas critiquen muchas veces el eurocentrismo y la ignoranciá de sus paisanos con respecto a otras culturas, ellos mismos ven a México exclusivamente en función de una verificación de sus teorías sobre las culturas y el arte supuestamente primitivos. Aun ellos buscan en México el paraíso perdido, el lugar para la realización de sus utopías. 10

Como he demostrado en esta introducción al tema de la imagen de México en las literaturas y el cine europeo y estadunidense del siglo XX, en la mayoría de 
los escritos y de las películas sobre México prevalecen imágenes que ven al otro como el buen salvaje o como un ser primitivo y bárbaro. En las representaciones artísticas de muchos extranjeros, México se transforma en el lugar de la rea. lización fantástica tanto de las utopías positivas como negativas. Maryse Holder, que viaja a México en los años 70, expresa de vez en cuando en su novela Give Sorrow Words (1979) que el acto de escribir literatura debe ser únicamente la creación de metáforas. A mi modo de verlo, esta creación de las grandes metáforas a partir de una experiencia limitada de otra cultura, termina precisamente en la repetición de los estereOtipos y clichés del México bárbaro, del México paradisíaco y del México infernal, que, al menos en parte, definen las visiones del país en el extranjero hasta nuestros días.

\section{Notas}

$1 C f$ los numerosos trabajos de James Clifford y Clifford Geertzal respecto, sobre todo James Clifford (1988).

2 Cj. entre otros, a Edward W. Said (1991) y. Michael Wiener (1990); yel catálogo de la exposición Exotische Welten - Europiiische Phantasien.

3 Para una crítica de las posiciones ahistóricas de Todorov, ef Rolena Adorno (1991) y Friedhelm Schmidt (1996, 212-214).

4 Para una interpretación más detallada de Lije 01 Villa, el Margarita de Orellana (1991, 88-94).

5 Respecto de los cambios generales de la percepción de América Latina en los Estados Unidos durante la era de la Good Neighborhood Policy. cj. Pike (1992.258-296).

6 Para una interpretación más detallada de The Magnificent Seven, el Welle (1992, 171·172) YEdward Buscombe (1993,15-24).

7 Una operación textual similar se puede comprobar en los textos de Gustave Flaubert sobre el Oriente.

s Pero hay que destacar las diferencias entre las obras de Lawrence. Huxley y Greene. por una parte, y la novela de Lowry por otra. Aunque el motivo del México infernal aparezca también en Under the Volcano, Lowry ya reconoce la operación psicológica de utilizar al país descrito como un espejo de la mente del narrador. Así, cuando escribe que «el nombre de esta tierra es el infierno,» afirma al mismo tiempo lo siguiente: «Claro que no está en México. sino en el corazón» $(1993,44)$.

$9 C f$ para una interpretación detallada de la novelística de Lawrence, Huxley, Lowry y Greene sobre México, George Woodcock (1956). Ronald G. Walker (1978, 1984).

$10 C f$ para una interpretación con un enfoque distinto y más favorable en cuanto a las imágenes de México en los textos de los surrealistas franceses,. Klengel (1994).

\section{Obras citadas}

Adorno, Rolena. 1991. «Todorov y de Certeau: la alteridad y la contemplación del sujeto.» Revista de Crítica Literaria Latinoamericana 17. 33: 51-58. . 
Artaud, Antonin. 1963. «La pintura de María Izquierdo.» Revista de la Universidad de México 17. 12: 22.23.

- - O 1968. «México y el espíritu femenino: María Izquierdo.» Revista de la Universidad de México 22. 6: 2-4.

Badenberg, Nana. 1992. «Wandbilder - Bilderwandel. Diego Rivera im BHck seiner europäischen Betrachter.» Schmidt 130-159.

Bartlett, Norman. 1964. «A. Huxley and O. H. Lawrence.» Australian Quarterly 36, 1: 76-84.

Breton, André. 1946. «Frida Kahl0.» El Hijo Pródigo 12, 38: 96.

Brotherston. J.G. 1972. «Revolution and the Aneient Líteratwe of Mexico, for O.H. Lawrenee and Antonin Artaud.» Twentieth Century Literature 18, 3: 181-189.

Buscombe, Edward. 1993. «The Magnificent Seven.» Mediating Two Worlds. Cinematic Encounters in the Americas. Eds. John King, Ana M. López, Manuel Alvarado. London: British Film Institute. 15-24.

Certeau, Michel de. 1986. Heterologies. Discourse on the Other. Minneapolis: U of Minnesota P.

CHfford, James. 1988. The Predicament of Culture. Twentieth Century Ethnography, Literature and Art. Cambridge: Cambridge UP.

Exotische Welten - Europäische Phantasien. 1987. Stuttgart: Cantz.

García Riera. Emilio. 1987. Vol. 1. México visto por el cine extranjero. México: EralUniversidad de Guadalajara.

Geertz, Clifford. 1988. Works and Lifes. The Anthropologist as Author. Stanford: Stanford UP.

--O 1989. El antropólogo como autor. Barcelona: Paid6s.

Geertz, C., J. Clifford et al. 1991. El surgimiento de la antropología posmodema. México: Gedisa Mexicana.

Greene, Graharn. 1965. The Powerand the Glory. New York: The Viking Press.

- - O 1990. El poder y la gloria. Barcelona: Caralt.

Holder, Maryse. 1979. Give Sorrow Words. New York: Grove Press.

Huxley, Aldous. 1928. Point Counter Point. London: Chatto \& Windus.

- 1934. Beyond the Mexique Bay. Londori: Chatto \& Windus.

- O 1950. Eyeless in Gaza. London: Chauo \& Windus.

--O 1962. «Introductíon.» O.H. Lawrence. 2 vols. The Collected Letrers of D.H. Lawrence. London: Heinemann. 1247-1268.

- - O 1969. «Contrapunto.» 3 vols. Obras completas. Barcelona: Plaza \& Janés. 11-575.

- O 1970. «Ciego en Gaza.» Vol. I. Obras completas. Barcelona: Plaza \& Janés. '787-1276.

Jarneson, Fredric. 1988. «Metacornrnentary.» The Ideologies of Theory. Essays 1971. 1986. Volume 1: Situations ofTheory. Minneapolis: U ofMinnesotaP. 3-16.

Klengel, Susanine. 1994. Amerika-Diskurse der Surrealisten. «Amerika» als Vision und als Feld heterogener Eifahrungen. Stuttgart: Metzler.

Lawrence, O.H. 1960. «Mornings in Mexico.\}\} Momings in Mexico and Etruscan Places. Harrnondsworth: Penguin Books. 
--.1978. La serpiente emplumada. Tlahuapan: Premià. 1982. Mañanitas mexicanas. Barcelona: Laertes.

- - O 1990. The Plumed Serpent (Quetzalcoatl). London: Penguin Books.

Le Clézío, Jean Marie Gustave. ]980. «Antonin Artaud: el sueño mexicano.» Études Mexicaines 3: 19-27.

Lowry. Malcolm. 1990. Under the Volcano. London: Pan Books.

--. 1993. Bajo el volcán. México: Era.

Mistron, Deborah E. 1983. «The Role of Pancho Villa in the Mexican and American Cinema.» Studies in Latin American Popular Culture 2: 1-13.

Monsiváis, Carlos. 1984. «Los viajeros y la invención de México.» Aztlán. Intemational Joumal of Chicana Studies Research 15,2: 201-229.

OreHana, Margarita de. 1991. La mirada circular. El cine norteamericano de la Revo. lución Mexicana 1911-1917. México: Joaquín Morliz.

Ortega y Gasset, José. 1970. La deshumanización del arte y otros ensayos estéticos. Madrid: Revista de Occidente.

Pacheco, losé Emilio. 1964. «El México de los novelistas ingleses.» Revista de la Universidad de México 18, 12: 19-22.

Péret, Benjamín. 1960. «Introduction.» Anthologie des mythes, légendes et cantes popu. laires d'Amérique. Ed. Benjamín Péret. Paris: Albín Michel. 7-38.

Pichardie, Jean Pau!. 1988. D. H. Lawrence: La tematian utopique. De Rananim au Serpent a plumes. Rouen: Publications de l'Université de Rouen.

Pike, Fredrick B. 1992. The United States ami Latin America. Myths ami Stereotypes of Civilization and Nature. Austin: U. ofTexas P.

Reed, John. 1969. Insurgent Mexico. New York: Simon \& Schuster.

- 1982. México insurgente. México: Porrúa.

Said, Edward W. 1991. Orientalism Westem Con.ceptions ofthe Orient.London: Penguin Books. Schimmelpfennig, Nina. 1992. «Droben wíe drunten - Sternenwelten. Notizen zu Wla. dimir Majakowskis Mexiko-Entdeckung.» Schmidt 81-90.

Schmidt, Friedhelm, ed. 1992. Wildes Paradies - Rote Hölle. Das Bild Mexikos in Literatur und.Film der Modeme. Bielefeld: Aisthesis.

- - O 1992. «Fem der Utopie undjenseits modemer Zivilísation. Mexiko in den Reiseberichten von D. H. Lawrence und Aldous Huxley.» Schmidt 61-80.

--O 1996. Stimmen femer Welten. Realismus und HeterogeniUit in der Prosa Juan Rulfos und Manuel Scorzas. Bielefeld: Aisthesis.

Schneider. Luis Mario. 1973. «Introducción.» Dos poetas rusos en México; Balmont y Maiakovski. Ed. L.M. Schneider. México: SepSetentas. 9-39.

Spengler, Oswald. 1923. La decadencia de Occidente. Bosquejo de Una morfología de la historia universal. 4 vols. Madrid: Calpe.

--O 1970. Der Untergang des Abendlandes. Umrisse einer Morpholagie der Weltgeschichte. 2 vols. München: dtv.

Spivak, Gayatri Chakravorti. 1988. «Can the Subaltem Speak?» Marxism and the Interpretation ofCulture. Eds. Gary Nelson y Lawrence Grossberg. Chicago: U oflllinQis P. 271-313. 
Todorov, Tzvetan. 1982. La conquête de l'amérique. La question de l'autre. París: Éditions du Seuil.

1988. La conquista de América. La cuestión del otro. México: Siglo XXI.

Turner, John Kenneth. 1969. Barbarous Mexico. Austin: U of Texas P.

1974. México bárbaro. México: Costa-Amic.

Valle, Rafael Heliodoro. 1986. «Diálogo con André Breton.» México en el Arte 14: 119-122.

Walker, Ronald G. 1978. Infernal Paradíse. Mexico and the Modem English Novel. Los Angeles, Berkeley: U of California P.

1984. Paraíso infernal. México y la novela inglesa moderna. México: Fondo de Cultura Económica.

Welle, Astrid. 1992. «Großer Bruder, kleine Schwester. Die Überschreitu'ng der frontier nach Mexiko ¡m US-amerikanischen Western.» Schmidt 160-182.

Wiener, Michael. 1990.1konographie des Wilden. München: Trickster.

Woodcock, George. 1956. «Mexico and the English Novelist.» The Western Review 21, 1: 21-32.

Zytaruk, George J. ed. 1970. The Questfor Rananim. D. H. Lawrence's Letters to S. S. Kateliansky 1914-1930. Montreal: McGill-Queen's UP. 